\title{
Simulación de una Estrategia en Implementación de Vehículos Eléctricos en el Transporte Terrestre del Ecuador en el Horizonte $2014-2035$
}

\author{
Vargas, Carlos ${ }^{1}$ iD ; Guamán, Jesús ${ }^{1}{ }^{\text {iD }}$; Ríos, Alberto ${ }^{1}{ }^{*}$ (iD) ; Otorongo, Manuel ${ }^{1}$ (iD \\ ${ }^{1}$ Universidad Técnica de Ambato, Facultad de Ingeniería en Sistemas, Electrónica e Industrial, Ambato, Ecuador.
}

\begin{abstract}
Resumen: En el Ecuador, el principal consumidor final de energía es el sector transporte. En el año 2014, el consumo de energía alcanzó el $42 \%$ del consumo nacional total. El Estado ecuatoriano debe importar un importante volumen de derivados de petróleo para garantizar la demanda total de los combustibles fósiles empleados en el sector transporte. Además, el expendio de combustible fósil está subvencionado, implicando un sustancial gasto de recursos económicos. En el presente artículo, se simula la estrategia de una futura implementación de vehículos eléctricos en el sistema nacional de transporte terrestre. El estudio de prospectiva y planificación energética en el sector transporte se realizó con ayuda del Modelo de Simulación y Análisis de la Matriz Energética - SAME, perteneciente a la Organización Latinoamericana de Energía OLADE. A través de un tablero virtual, se simula en el año 2035 la sustitución de combustibles fósiles: gasolina y diésel por electricidad, minimizando así el volumen de importaciones de los derivados del petróleo. El objetivo del presente trabajo es demostrar la viabilidad técnica de electrificación del sector de transporte y desacoplamiento de los derivados del petróleo. Como resultados de una primera aproximación estratégica en esta sustitución implicaría una reducción de 86.223,0 kbep de diésel del consumo nacional, además, una importante reducción de importaciones de gasolina. De esta manera, al año 2035, sólo se importaría alrededor de 19.650,9 kbep, destinados al consumo de sectores comercial, residencial y construcción.
\end{abstract}

Palabras clave: Combustibles Fósiles, Consumo Energético, Sustitución Eléctrica, Matriz Energética.

\section{Simulation of a Strategy in Electric Vehicles Implementation in the Land Transport of Ecuador in the Horizon 2014 - 2035}

\begin{abstract}
In Ecuador, the main final consumer of energy is the transport sector. In 2014, energy consumption reached $42 \%$ of total national consumption. The Ecuadorian State must import a significant volume of oil to guarantee the total demand of fossil fuels used in the transport sector. In addition, the fuel expense is subsidized, implying a substantial expenditure of economic resources. In the present article, the strategy of a future implementation of electric vehicles in the national terrestrial transport system is simulated. The study of prospective and energy planning in the transport sector was carried out with the help of the Simulation and Analysis Model of the Energy Matrix SAME, belonging to the OLADE Latin American Energy Organization. Through a virtual board, it simulates in the year 2035 the substitution of fossil fuels: gasoline and electricity for electricity, thus minimizing the volume of imports of petroleum derivatives. The objective of this work is to demonstrate the technical viability of the electrification of the transport and decoupling sector of petroleum derivatives. As a result of a first strategic approach in this substitution, a reduction of $86.223,0 \mathrm{kbep}$ of diesel of national consumption, would eliminate gasoline imports. Thus, by the year 2035, only about 19.650,99 kbep would be imported, destined for the consumption of commercial, residential and construction sectors.
\end{abstract}

Keywords: Fossil fuels, Energy consumption, Electrical Substitution, Energy Matrix.

\section{INTRODUCCIÓN}

En el año 2014, el consumo final de energía en el Ecuador alcanzó los 101 millones de barriles equivalentes de petróleo. El sector transporte, con un consumo final de energía equivalente a 42 millones de barriles, es el principal sector consumidor de energía con un $42 \%$ del total (Estratégicos, 2015).

Asimismo, es importante indicar, que el consumo de energía en el sector transporte se incrementó en una tasa promedio anual del 4,3\% en el periodo 2004-2014, Figura 2, debido 
fundamentalmente al incremento del parque automotor del Ecuador y al crecimiento económico experimentado por el país en el periodo analizado.

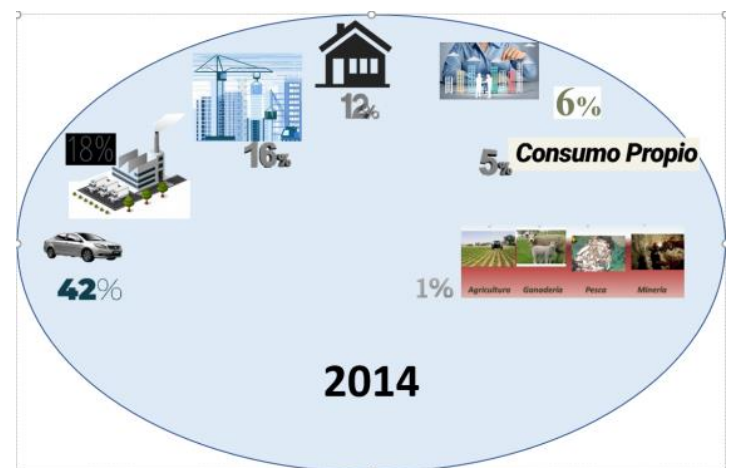

Figura 1. Evolución y estructura del consumo de energía final por sectores en el Ecuador a diciembre del año 2014 (Estratégicos, 2015).

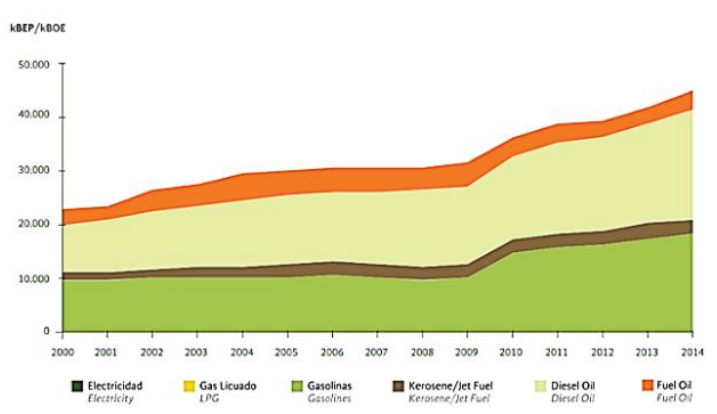

Figura 2. Evolución y estructura del consumo final de energía en el sector transporte en el Ecuador a diciembre del año 2014 (Estratégicos, 2015).

En el año 2014, el 93\% del consumo final de energía en el sector transporte correspondió principalmente a tres derivados de petróleo: diésel, gasolinas y fuel oil, como se muestra en la Figura 3, básicamente empleados en el sector transporte terrestre y marítimo. En el transporte marítimo se utilizan principalmente dos tipos de combustibles: diésel oíl y fuel oúl, quedando limitado el uso del gas oíl a motores rápidos de poca potencia para generación de energía eléctrica $\mathrm{y}$ en buques de recreo. El 7\% restante del consumo, fundamentalmente empleado en el transporte aéreo, es cubierto por el kerosene/jet fuel. La participación del GLP y de la electricidad en cubrir la demanda de energía en el transporte es ínfima, $0,2 \%$ y $0,01 \%$, respectivamente.

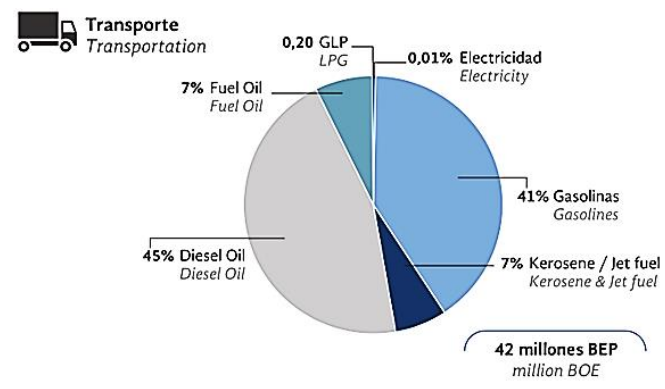

Figura 3. Estructura del consumo de energía por sectores en el Ecuador a diciembre del año 2014 (Estratégicos, 2015).

En el Ecuador, para garantizar la demanda total de diésel, gasolinas y fuel se debe importar importantes volúmenes de derivados de petróleo, necesarios para la movilidad y transporte de alimentos y personas, y que además son subvencionados por el Estado, implicando un sustancial gasto de recursos económicos. En la Figura 4, se observa la oferta y demanda de derivados de petróleo a nivel nacional en el año 2014. El Ecuador importó el $69 \%$ y el $60 \%$ del total de la demanda de diésel y gasolinas en el año 2014, respectivamente. En el caso del Gas Licuado de Petróleo, GLP, el $83 \%$ de la demanda total es cubierta por importaciones. Tan sólo la demanda de fuel oíl y kerosene/Jet Fuel es cubierta en un $94 \%$ y $91 \%$, respectivamente, por producción obtenida en refinerías nacionales, Figura 4.

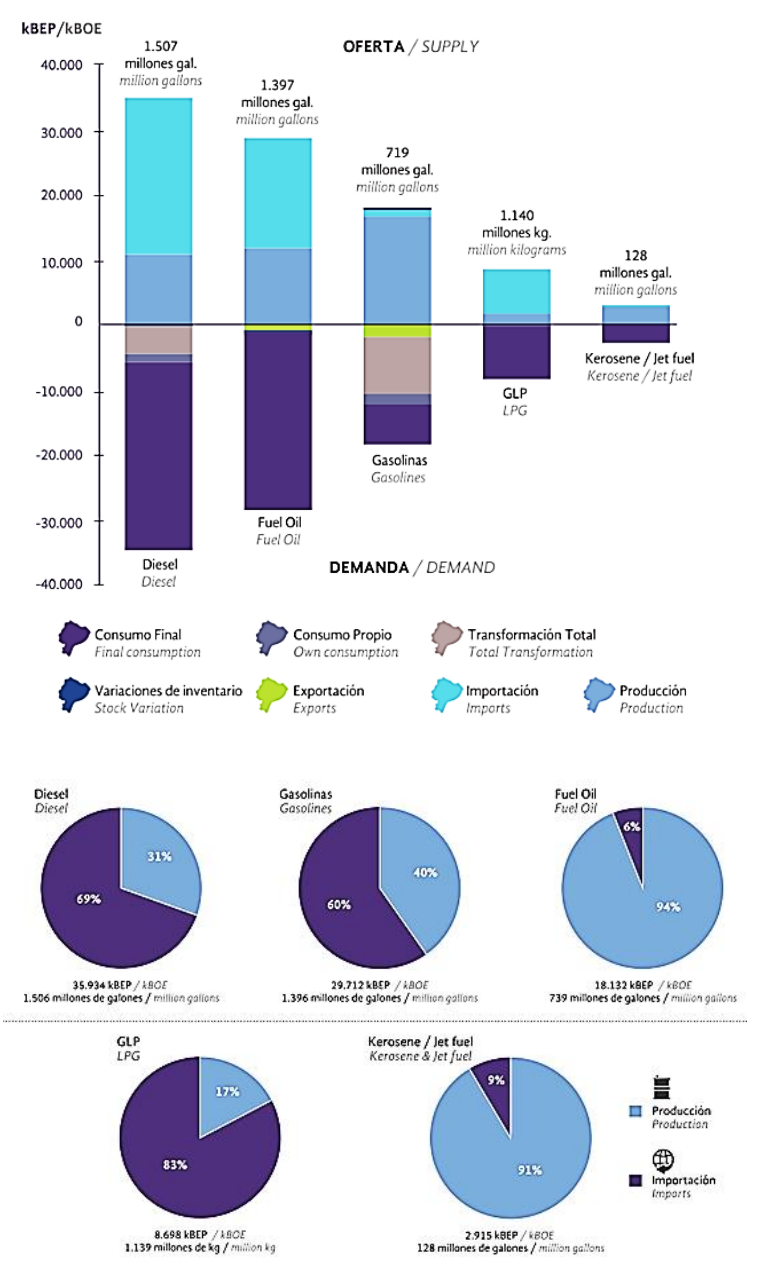

Figura 4. Estructura de la oferta y demanda de derivados de petróleo a diciembre del año 2014 (Estratégicos, 2015).

En el Ecuador, en el año 2014, el consumo final de energía en el sector transporte fue de 42 millones de bep. El transporte terrestre demanda el $86 \%$ del total de productos derivados de petróleo. El transporte aéreo y marítimo consumen el 6 y $8 \%$, respectivamente, de la demanda final de energía empleada en el sector transporte, Figura 5. Asimismo, en la Figura 5, se observa que el transporte de carga pesada y liviana son los mayores consumidores de derivados de petróleo, asumiendo un $70 \%$ del total de la demanda final de energía en el sector transporte.

Es importante indicar que los vehículos de transporte de personas como buses, taxis, jeeps y autos representan, conjuntamente, el $26 \%$ del total de la demanda final de 
energía en el sector transporte. La demanda de energía en el sector transporte terrestre en el año 2014 fue de 36 mil 558 kbep.

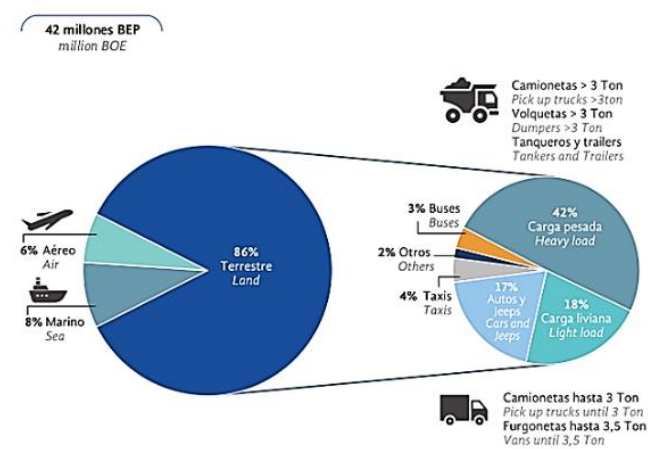

Figura 5. Estructura de la demanda final de energía por tipo de transporte a diciembre del año 2014 (Estratégicos, 2015).

En la Figura 6, se presenta el porcentaje de la demanda final total de diésel y gasolinas empleadas en el sector transporte. En el Ecuador, a finales de diciembre del año 2014, el 65\% y $96 \%$ del consumo final total de diésel y gasolinas correspondió al sector transporte, respectivamente. En el año 2014, se consumieron 811,4 millones de galones de gasolinas y 811,8 millones de galones de diésel, Figura 6.

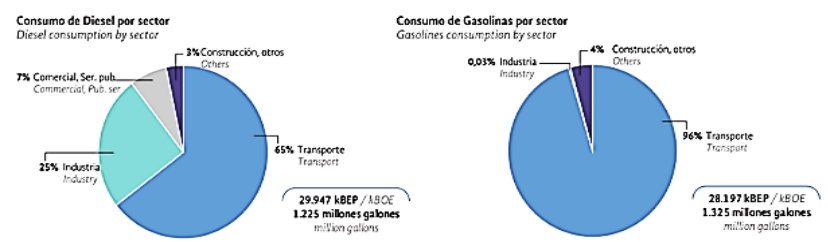

Figura 6. Estructura de la demanda por sectores económicos de diésel y gasolinas a diciembre del año 2014 (Estratégicos, 2015).
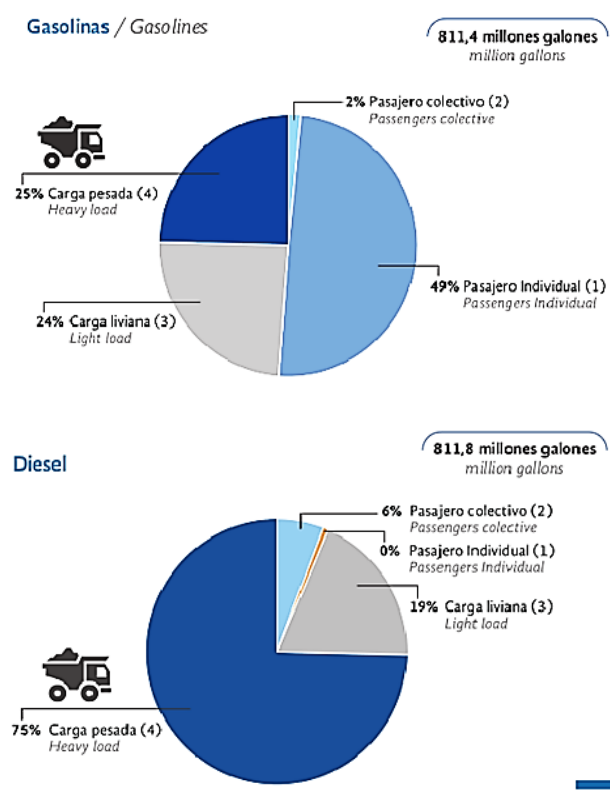

Figura 7. Distribución porcentual del consumo de diésel y gasolinas por tipo de vehículo (Estratégicos, 2015).

Asimismo, en la Figura 7, se presenta la distribución porcentual del consumo de diésel y gasolinas por tipo de vehículos. Se verifica que los vehículos de carga liviana y pesada representan un significativo porcentaje de la demanda final de energía, tanto de diésel como de gasolinas. Así, el transporte de carga liviana y pesada representa el $49 \%$ del consumo final de gasolina, mientras que los vehículos de carga pesada y liviana consumen el $94 \%$ del consumo final de diésel. Destaca el importante consumo de gasolina en vehículos de uso privado, con un $49 \%$ del consumo final de gasolina.

En la Tabla 1, se presenta la evolución de la demanda de energía en el sector transporte por tipo de combustible en el Ecuador entre los años 2004 y 2014 en kbep.

Tabla 1. Evolución de la demanda de energía en el sector transporte por tipo de combustible (Estratégicos, 2015).

\begin{tabular}{|c|c|c|c|c|c|c|c|c|c|c|c|c|}
\hline & 2004 & 2005 & 2006 & 2007 & 2008 & 2009 & 2010 & 2011 & 2012 & 2013 & 2014 & 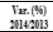 \\
\hline $\begin{array}{l}\text { Electricidad } \\
\text { Electricity }\end{array}$ & 6 & 6 & 6 & 6 & 6 & 6 & 6 & 6 & 6 & 6 & 6 & \\
\hline $\begin{array}{l}\text { Gas Licuado } \\
\text { LPG }\end{array}$ & - & - & - & - & 8 & 72 & 88 & 75 & 82 & 73 & 86 & 17,5 \\
\hline $\begin{array}{l}\text { Gasolinas } \\
\text { Gasolines }\end{array}$ & 9.497 & 9.852 & 9.931 & 9.488 & 9.195 & 9.658 & 13.759 & 14.875 & 15-611 & 16.452 & 17.228 & 4,7 \\
\hline $\begin{array}{l}\text { KeroseneJet Fuel } \\
\text { Keronese/Jet Fuel }\end{array}$ & & 2.313 & 2.417 & 2.531 & 2.543 & 2.479 & 2.483 & 2.520 & 2.430 & 2.748 & 2.765 & 0,6 \\
\hline $\begin{array}{l}\text { Diesel Oil } \\
\text { Diesel Oil }\end{array}$ & 11.512 & 12.041 & 12.492 & 12.925 & 13.207 & 13.676 & 14.540 & 15.775 & 16.258 & 17.638 & 19.330 & 9,6 \\
\hline $\begin{array}{l}\text { Fuel oil } \\
\text { Fuel Oill }\end{array}$ & 4.892 & 4.624 & 4.354 & 4.312 & 4.302 & 4.320 & 3.788 & 3.741 & 3.088 & 2.837 & 3.098 & 9,2 \\
\hline $\begin{array}{l}\text { Total } \\
\text { Totat }\end{array}$ & 27.959 & 28.836 & 29.200 & 29.262 & 29.261 & 30.211 & 34.663 & 36.993 & 37.474 & 39.754 & 42.513 & 6,9 \\
\hline
\end{tabular}

De la Tabla 1 se observa que el consumo de electricidad en el sector se ha estancado en $6 \mathrm{kbep}$, los mismos que corresponden al único sistema de transporte electrificado urbano que tiene el Ecuador, trolebús que funciona en la ciudad de Quito, con un recorrido de 24 kilómetros.

Actualmente, el trolebús de Quito cuenta con un total de 113 unidades articuladas. Se calcula que un promedio de 83 unidades, circulan por hora, mientras que en horario pico el número aumenta a 96 unidades por hora. Es importante indicar que, en el Ecuador, a finales del año 2014 existían 35 vehículos eléctricos matriculados en el Ecuador (INER, 2017). El consumo eléctrico de estos vehículos no afecta sustancialmente la demanda total de electricidad en el sector transporte. No obstante, en un proceso de electrificación del transporte de personas y mercancías, el consumo de electricidad deberá sustituir a los derivados de petróleo en un horizonte de 20-30 años.

En el caso del GLP, utilizado en el sector transporte, a pesar de su rápido incremento entre el año 2008 y 2009, entre el año 2010 y 2014 su empleo se ha estancado por debajo de los $88 \mathrm{kbep}$, correspondiente a la demanda de 449 vehículos a GLP, debido al interés del gobierno de sustituir el subsidio del GLP. Esto significa que el consumo de GLP se extinguirá a medida que el Estado ecuatoriano implemente políticas de sinceramiento de precios del GLP. Entre los años 2004 y 2014, el consumo de fuel oil ha experimentado un importante retroceso, debido principalmente a la modernización de los vehículos de carga liviana y pesada. Actualmente su principal uso en el sector transporte se encuentra en el transporte marítimo. El consumo de fuel oil, en el sector transporte, en 10 años se ha reducido de 4892 kbep a 3098 kbep.

Fuera del sector transporte, el fuel oil se emplea principalmente para la generación eléctrica y en calderas, hornos y motores estacionario. En el año 2014, el fuel oil empleado para la generación eléctrica representó el 28,6\% de 
la energía secundaria empleada, superior incluso a la energía primaria hidráulica. La integración al sistema eléctrico del Ecuador de la central hidroeléctrica Coca Codo-Sinclair redujo al mínimo la participación del fuel oil en la generación eléctrica, quedando como unidades de reserva de emergencia Tan en el sector de transporte marítimo como en el sector transporte aéreo, el uso de kerosene/jet fuel, al parecer, no dispone de un sustituto energético comercialmente viable en la actualidad. Aunque existen innovadoras experiencias internacionales de sustitución de combustibles fósiles empleados en el sector marítimo y aéreo, una estrategia de sustitución de fuel oil y kerosene/jet fuel deberá analizar detalladamente la evolución tecnológica de las propuestas actualmente existentes. En el Ecuador, el consumo de kerosene/jet fuel se incrementado muy lentamente en los últimos años, asociado al aumento de los vuelos nacionales e internacionales. Así, entre 2004 y 2014, la demanda de kerosene/jet fuel paso de 2 mil $313 \mathrm{kbep}$ a 2 mil 765 kbep. Por otro lado, en el Ecuador, el consumo de gasolinas casi se ha duplicado entre el año 2004 y 2014, pasando de 9 mil 497 kbep a 17 mil 228 kbep. Una situación parecida ha experimentado en el consumo de diésel, que ha pasado de 11 mil 512 kbep a 19 mil 330 kbep. Por tanto, se ha producido un significativo incremento del consumo de diésel y gasolina en el sector transporte.

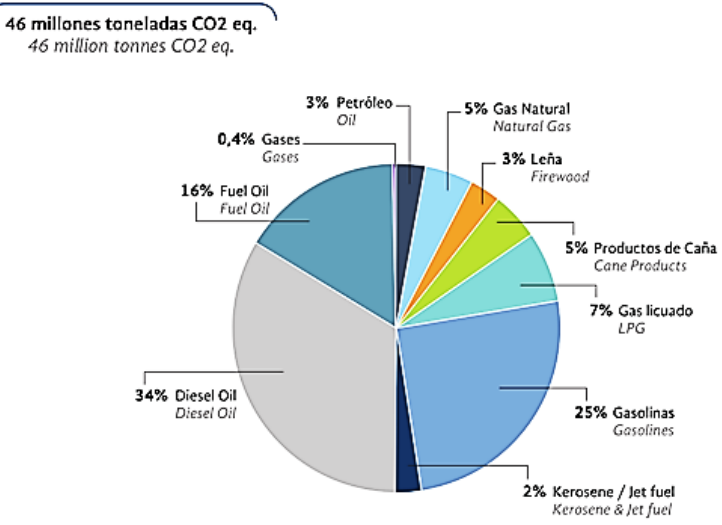

Figura 8. Estructura de las emisiones contaminantes sectores y por tipo de combustible (Estratégicos, 2015).

Finalmente, el sector transporte es el principal contaminante de emisiones de efecto invernadero, con un 39\% del total de emisiones al año 2014, Figura 8. Las centrales eléctricas y los autoproductores conforman el segundo mayor emisor de contaminantes del país con una participación del 14\%. Por fuente de energía, el diésel es el principal energético contaminante, con un $34 \%$ del total de emisiones, seguido por las gasolinas con el $25 \%$ y el fuel oil con el $16 \%$, Figura 8. En el análisis realizado surge la hipótesis que la soberanía e independencia energética del país, así como la reducción de las emisiones contaminantes para las futuras generaciones de Ecuador se puede alcanzar a través de plantear estrategias de sustitución de combustibles fósiles en el sector transporte por soluciones eléctricas, que permitan garantizar un mejor servicio de movilidad en el país.

En una estrategia de sustitución de combustibles fósiles, en la actualidad, los vehículos convencionales de carga pesada y liviana podrían ser reemplazados por innovadores vehículos eléctricos, con almacenamiento de energía eléctrica en baterías y con catenarias análogas a los tranvías y trolebuses, o por un sistema de transporte ferroviario electrificado. Asimismo, desde una perspectiva tecnológica, los buses, taxis, jeeps y autos pueden ser sustituidos por vehículos eléctricos. La única limitación existente, actualmente en el Ecuador, es la falta de una infraestructura masificada de recarga de vehículos eléctricos privados y públicos. En una estrategia de sustitución de combustibles fósiles en el sector transporte a largo plazo, el diésel y la gasolina son los dos principales combustibles para sustituir en una estrategia de implementación de tecnologías limpias y sostenibles en el sector transporte del Ecuador.

La implementación de la estrategia propuesta permitiría a la economía ecuatoriana, altamente dependiente de este recurso natural, reducir su vulnerabilidad energética un entorno geopolítico internacional complejo, disponiendo además de una nueva fuente de ingresos económicos.

En este contexto se planea una simulación de una Estrategia en Implementación de Vehículos Eléctricos en el Transporte Terrestre del Ecuador en el Horizonte 2014 - 2035. Para ello se proponen la siguiente metodología:

Recolección de la información del consumo energético del parque automotor del Ecuador en el año base 2014.

Evaluación del consumo de energía eléctrica que implicaría la sustitución del parque automotor del Ecuador.

Propuesta de diferentes escenarios para la sustitución del sistema de trasporte convencional con un sistema de trasporte electrificado.

Simulación de los diferentes escenarios que tratan de minimizar el consumo de combustibles fósiles y sustituirse por energía eléctrica con ayuda del Modelo de Simulación y Análisis de la Matriz Energética SAME de OLADE.

Análisis de los resultados de la simulación la estrategia de implementación de vehículos eléctricos en el transporte terrestre

\section{CONSUMO ENERGÉTICO DEL PARQUE AUTOMOTOR DEL ECUADOR}

En el año 2014, se matricularon en el país 1 millón 752 mil 712 vehículos, según el Anuario de Estadísticas de Transportes 2014 (INER, 2017). En la Tabla 2 se presenta el parque automotor del Ecuador a finales del año 2014 por tipo de vehículos y combustibles empleados. Se observa que en el parque automotor predominan los vehículos a gasolina con más de un millón 553 mil unidades. En segundo lugar por número de unidades se encuentran los vehículos a diésel con más de 194 mil 900 unidades. Entre ambos tipos de combustible conforman el $99,74 \%$ de todas los vehículos del sector transporte terrestre del Ecuador, Figura 9. El restante 0,26\% corresponde a 4055 vehículos híbridos, 449 unidades a GLP y 35 autos eléctricos, Figura 10. 
Tabla 2. Estructura del parque automotor del Ecuador por tipo de vehículo y combustible empleado, elaboración propia.

\begin{tabular}{|c|c|c|c|c|c|c|}
\hline \multirow{2}{*}{$\begin{array}{l}\text { Tipo de } \\
\text { Vehículo }\end{array}$} & \multicolumn{6}{|c|}{ Tipo de Combustible } \\
\hline & Diésel & Gasolina & Híbrido & $G L P$ & Eléctrico & Total \\
\hline Automóvil & 1233 & 526274 & 1833 & 170 & 11 & 529521 \\
\hline Autobús & 11092 & 206 & & 1 & 1 & 11300 \\
\hline Camión & 74389 & 4261 & & 1 & 1 & 78652 \\
\hline Camioneta & 63749 & 304951 & 93 & 92 & 5 & 368890 \\
\hline $\begin{array}{c}\text { Furgoneta } \\
\text { de Carga }\end{array}$ & 13744 & 18493 & & 5 & & 32242 \\
\hline $\begin{array}{c}\text { Furgoneta } \\
\text { de } \\
\text { Pasajeros }\end{array}$ & 2238 & 39070 & 46 & 20 & & 41374 \\
\hline Jeеp & 4950 & 253767 & 2080 & 66 & 14 & 260877 \\
\hline Motocicleta & 91 & 404985 & 2 & 94 & 1 & 405173 \\
\hline Tanquero & 2384 & 127 & & & & 2511 \\
\hline Trailer & 6839 & 76 & & & 2 & 6917 \\
\hline Volqueta & 9646 & 296 & & & & 9942 \\
\hline Otros & 4587 & 725 & 1 & & & 5313 \\
\hline Total & 194942 & 1553231 & 4055 & 449 & 35 & 1752712 \\
\hline
\end{tabular}

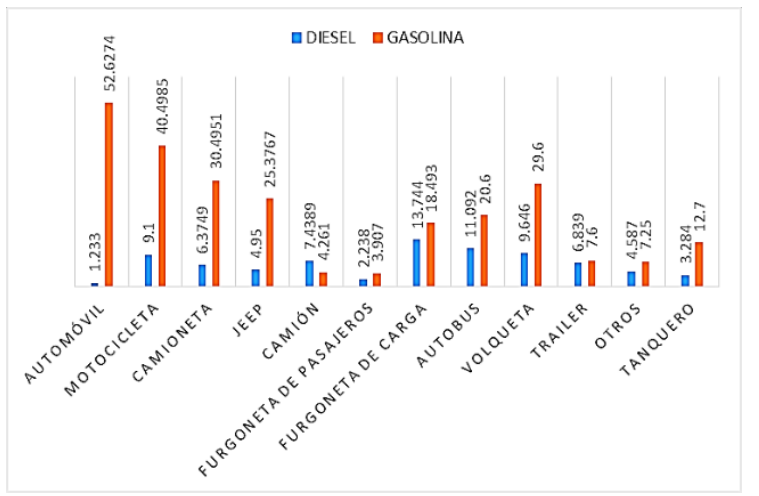

Figura 9. Estructura del parque automotor del Ecuador por tipo de vehículo para motores Diésel y Otto, elaboración propia.

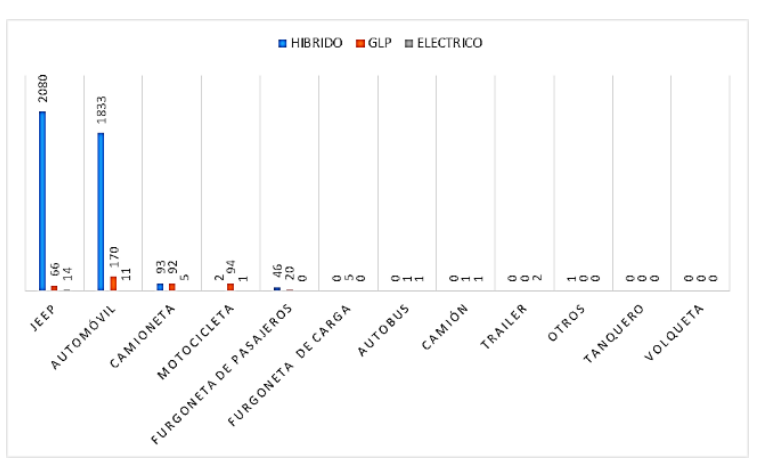

Figura 10. Estructura del parque automotor del Ecuador por tipo de vehículo para vehículos híbridos, GLP y eléctricos, elaboración propia.
Para simplificar el cálculo del consumo energético de los vehículos del parque automotor en el Ecuador a sustituir por vehículos menos contaminantes y más eficientes, en una simulación de estrategia de implementación de transporte sostenible, sólo se evaluará el consumo de energía fósil de los diferentes vehículos a diésel y a gasolina del parque automotor (Garc, Direcci, Estudios, Semana, \& Econom, 2013). El cálculo del consumo energético anual para cada tipo de vehículo, diésel y gasolina, exige disponer del rendimiento energético por kilómetro de los diferentes vehículos evaluados, tanto con motor Otto como con motor Diésel. Asimismo, es necesario disponer de un promedio aproximado de los kilómetros recorridos anuales para los diferentes tipos de vehículos evaluados En la Tabla 3 se presentan los valores de rendimiento por kilómetro por tipos de vehículos y combustible del parque automotor del Ecuador al año 2014, así como los recorridos promedios de los vehículos evaluados. Asimismo, en la Tabla 3 se calcula el consumo energético específico de cada tipo de vehículo evaluado tanto a diésel como a gasolina. En la Tabla 4 y en la Figura 11, se muestra el consumo energético anual del parque automotor del Ecuador en kbep, por tipo de vehículos para motores a diésel y gasolina en el año 2014. Los automóviles híbridos, los vehículos eléctricos y las unidades a GLP no se han considerado en el cálculo realizado por su escasa aportación energética al consumo total del parque automotor.

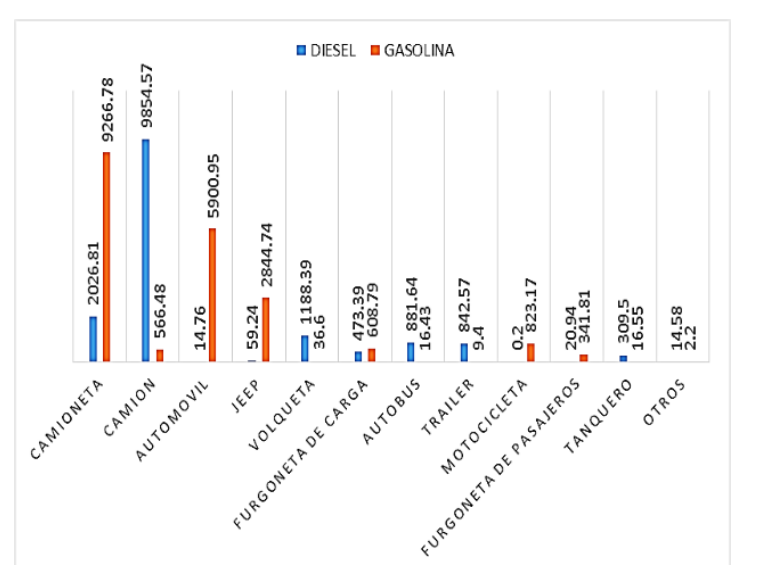

Figura 11. Consumo energético anual del parque automotor del Ecuador al año 2014 para motores Diésel y Otto, elaboración propia. 
Tabla 3: Rendimiento, recorrido promedio anual y consumo energético específico del parque automotor por tipo de vehículo.

Consumo Energético Anual por Tipo de Vehículo y Combustible

\begin{tabular}{|c|c|c|c|c|c|}
\hline \multirow{2}{*}{ Tipo de Vehículo } & \multicolumn{2}{|c|}{$\begin{array}{c}\text { Rendimiento } \\
\text { km/galón }\end{array}$} & \multirow{2}{*}{$\begin{array}{c}\text { Recorrido Promedio } \\
\text { Anual, } \mathrm{km}\end{array}$} & \multicolumn{2}{|c|}{$\begin{array}{c}\text { Consumo Específico Anual, } \\
\text { bep/vehículo }\end{array}$} \\
\hline & Diésel & Gasolina & & Diésel & Gasolina \\
\hline Automóvil & 45 & 42 & 16000,00 & 8,48 & 8,10 \\
\hline Autobús & 16 & 16 & 180000,00 & 268,26 & 239,30 \\
\hline Camión & 18 & 16 & 100000,00 & 132,47 & 132,95 \\
\hline Camioneta & 45 & 42 & 55000,00 & 29,14 & 27,86 \\
\hline Furgoneta de Carga & 45 & 42 & 72000,00 & 38,15 & 36,47 \\
\hline Furgoneta de Pasajeros & 45 & 42 & 16000,00 & 8,48 & 8,10 \\
\hline Jeеp & 45 & 42 & 15000,00 & 7,95 & 7,60 \\
\hline Motocicleta & 92 & 90 & 8610,00 & 2,23 & 2,03 \\
\hline Tanquero & 18 & 16 & 160000,00 & 211,96 & 212,71 \\
\hline Trailer & 18 & 16 & 162800,00 & 215,67 & 216,44 \\
\hline Volqueta & 18 & 16 & 160000,00 & 211,96 & 212,71 \\
\hline Otros & 45 & 42 & 10000,00 & 5,30 & 5,06 \\
\hline
\end{tabular}

Tabla 4: Consumo energético anual del parque automotor del Ecuador al año 2014, elaboración propia.

\begin{tabular}{|c|c|c|c|}
\hline \multirow{2}{*}{$\begin{array}{l}\text { Tipo de } \\
\text { Vehículo }\end{array}$} & \multicolumn{3}{|c|}{$\begin{array}{c}\text { Consumo Energético Anual Parque Automotor Ecuador } \\
\text { kbep }\end{array}$} \\
\hline & Diésel & Gasolina & Total \\
\hline Automóvil & 10,45 & 4264,61 & 4275,06 \\
\hline Autobus & 2975,53 & 49,30 & 3024,82 \\
\hline Camión & 9854,57 & 566,48 & 10421,06 \\
\hline Camioneta & 1857,91 & 8494,54 & 10352,46 \\
\hline Furgoneta de Carga & 524,37 & 674,35 & 1198,72 \\
\hline Furgoneta de Pasajeros & 18,97 & 316,60 & 335,57 \\
\hline Јеep & 39,34 & 1927,85 & 1967,20 \\
\hline Motocicleta & 0,20 & 824,13 & 824,33 \\
\hline Tanquero & 505,31 & 27,01 & 532,32 \\
\hline Trailer & 1474,95 & 16,45 & 1491,40 \\
\hline Volqueta & 2044,54 & 62,96 & 2107,51 \\
\hline Otros & 24,31 & 3,67 & 27,98 \\
\hline Total & 19330,46 & 17227,97 & 36558,43 \\
\hline
\end{tabular}


Los valores obtenidos de consumo energético anual del parque automotor del Ecuador corresponden a los porcentajes de consumo energético por agrupación de tipos de vehículos presentados en la Figura 5. Así, el $86 \%$ del consumo total de energía del sector transporte corresponde al sector de transporte terrestre igual a 36 mil 558 kbep (Yascaribay \& Vidal, 2016). Asimismo, el $60 \%$ del consumo total de energía en el sector transporte corresponde a la demanda energética de los vehículos de carga pesada - camionetas y volquetas mayores a 3 toneladas, tanqueros y tráileres - y de los vehículos de carga liviana - camionetas y volquetas menores a 3 toneladas y furgonetas -, sumando 25.452,6 kbep (Energ et al., 2014). Al emplear los datos del parque automotor, el consumo de 25.452,6 kbep corresponde a la suma de los consumos energéticos anuales de las unidades de camiones, camionetas, furgonetas de carga, tanqueros tráileres y volquetas, presentados en la Tabla 2. Asimismo, en la Figura 5 se indica que el consumo energético de autos y jeeps representan $17 \%$ del consumo total de energía en el sector transporte, igual a 7.211,57 kbep, mientras que los taxis, con un $4 \%$ del total de la demanda de energía en el transporte, consumen 1696,84 kbep. En total, según los datos del parque automotor de la Tabla 2, los vehículos - agrupados en autos y taxis - y los jeeps consumen el $21 \%$ del total de la demanda de energía en el sector transporte, igual a 8.908,41 kbep. Los buses, que agrupan autobuses y furgonetas de pasajeros, consumen un $3 \%$ del total de la demanda de energía total equivalente a 1.272,63 kbep (INER, 2014). Finalmente, el segmento otros, con un $2 \%$ de la demanda total del sector transporte, que incluye a motocicletas y vehículos de otra clase como vehículos de la policía, bomberos, ambulancias públicas y privadas, en el año 2014, consumió 848,42 kbep (INER, 2013).

\section{CONSUMO ENERGÉTICO DE LOS VEHÍCULOS DE SUSTITUCIÓN DE COMBUSTIBLES FÓSILES}

El consumo energético en el sector transporte del Ecuador puede ser reemplazado dos tipos de vehículos: los vehículos eléctricos y los vehículos a biocarburantes (IDAE Instituto para la Diversificación y Ahorro de la Energía, 2005). En la actualidad, todos los vehículos a diésel y a gasolina del parque automotor del Ecuador pueden ser reemplazados por vehículos eléctricos, en la Tabla 5 se presentan los valores de rendimiento, recorrido promedio, consumo energético específico y consumo energético del parque automotor del Ecuador si todos los vehículos convencionales del parque sean reemplazados por vehículos eléctricos. En la Figura 12, se muestra el consumo eléctrico anual del parque automotor del Ecuador en kbep, por tipo de vehículo eléctrico en el año 2014.

Una estrategia de implementación de vehículos eléctricos en el sector de transporte terrestre permitiría desencadenar al país del consumo de derivados de petróleo, Por otro lado, la masiva integración de vehículos eléctrico implica el diseño e instalación de una estructura de recarga eléctrica que garantice el suministro de energía eléctrica a los usuarios de vehículos eléctricos. Asimismo, exige la realización de estudios del potencial de recursos energéticos autóctonos que permitan garantizar la demanda de un sistema electrificado de transporte.

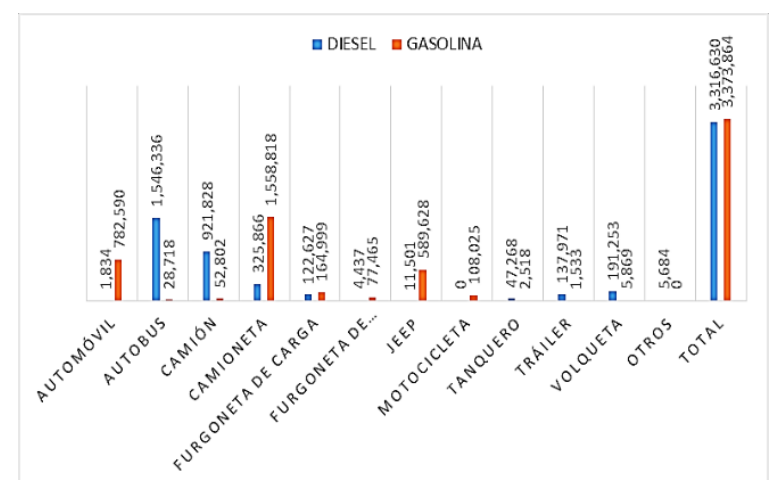

Figura 12. Consumo energético anual del parque automotor del Ecuador para vehículos eléctricos, elaboración propia.

\section{SIMULACIÓN DE ESCENARIOS DE IMPLEMENTACIÓN DE VEHÍCULOS SOSTENIBLES EN EL ECUADOR.}

La elevada dependencia del sector transporte de los derivados del petróleo y la contaminación medioambiental, asociada a los procesos de transformación final de los vehículos, exige la necesidad de implementar estrategias de sustitución de combustibles fósiles (INER, 2013). En la actualidad, existen las tecnologías de sustitución sostenible del transporte convencional que permitirá conformar un futuro sistema de transporte sostenible, basado en la integración de vehículos eléctricos y vehículos a biodiésel y/o etanol en sustitución de las unidades convencionales con motores de combustión Otto y Diésel.

En este sentido, se propone evaluar un escenario de sustitución de vehículos fósiles para un horizonte de análisis al año 2035, un escenario de transporte terrestre $100 \%$ eléctrico. Para la simulación de escenarios propuestos se empleará el software de simulación de escenarios energéticos SAME, Modelo de Simulación de la Matriz Energética, elaborado y desarrollado por la Organización Latinoamericana de Energía, OLADE (“SAME - OLADE," n.d.).

El sistema de planificación SAME es un modelo de simulación y análisis de la matriz energética que permite simular de manera integrada la implementación de diferentes políticas de desarrollo energético en un país o una región y observar sus efectos sobre los indicadores de sostenibilidad de su matriz energética. 
Tabla 5: Rendimiento, recorrido anual y consumo energético específico y anual del parque automotor por tipo de vehículo eléctrico.

\begin{tabular}{|c|c|c|c|c|c|c|}
\hline \multicolumn{7}{|c|}{ Consumo Energético Anual por Tipo de Vehículo Eléctrico } \\
\hline \multirow{2}{*}{ Tipo de Vehículo } & \multirow{2}{*}{$\begin{array}{c}\text { Rendimiento } \\
\mathrm{kWh} / \mathrm{km}\end{array}$} & \multirow{2}{*}{$\begin{array}{l}\text { Recorrido } \\
\text { Promedio } \\
\text { Anual, } k m\end{array}$} & \multirow{2}{*}{$\begin{array}{c}\text { Consumo } \\
\text { Específico Anual, } \\
\text { Bep }\end{array}$} & \multicolumn{2}{|c|}{$\begin{array}{c}\text { Consumo Energético Anual, } \\
\text { Kbep }\end{array}$} & \multirow{2}{*}{ Total } \\
\hline & & & & Diésel & Gasolina & \\
\hline Automóvil & 0,15 & 16000,00 & 1,487 & 1,834 & 782,590 & 784,424 \\
\hline Autobús & 1,25 & 180000,00 & 139,410 & 1546,336 & 28,718 & 1575,054 \\
\hline Camión & 0,20 & 100000,00 & 12,392 & 921,828 & 52,802 & 974,631 \\
\hline Camioneta & 0,15 & 55000,00 & 5,112 & 325,866 & 1558,818 & 1884,684 \\
\hline Furgoneta de Carga & 0,20 & 72000,00 & 8,922 & 122,627 & 164,999 & 287,626 \\
\hline Furgoneta de Pasajeros & 0,20 & 16000,00 & 1,983 & 4,437 & 77,465 & 81,902 \\
\hline Jeep & 0,25 & 15000,00 & 2,324 & 11,501 & 589,628 & 601,129 \\
\hline Motocicleta & 0,05 & 8610,00 & 0,267 & 0,024 & 108,025 & 108,049 \\
\hline Tanquero & 0,20 & 160000,00 & 19,827 & 47,268 & 2,518 & 49,786 \\
\hline Tráiler & 0,20 & 162800,00 & 20,174 & 137,971 & 1,533 & 139,504 \\
\hline Volqueta & 0,20 & 160000,00 & 19,827 & 191,253 & 5,869 & 197,122 \\
\hline Otros & 0,20 & 10000,00 & 1,239 & 5,684 & 0,898 & 6,583 \\
\hline Total & 3,25 & 955410,00 & 232,964 & 3316,630 & 3373,864 & 6690,494 \\
\hline
\end{tabular}

El modelo de simulación SAME exige la siguiente información:

- Balance de energía final para el año base, que puede ser un año histórico, actual o futuro.

- Información de las tecnologías de oferta de energía como: capacidad instalada, eficiencias medias, factores de planta, costos unitarios de producción, costos unitarios de inversión, factores de emisión de GEI, etc.

- Información de reservas y potenciales.

- Información de eficiencias relativas de tecnologías de uso final como cocción, iluminación, transporte, refrigeración, etc.

El sistema de simulación SAME presenta las siguientes funcionalidades:

- Realiza de manera simple proyecciones de estados factibles y coherentes de la matriz energética para un año futuro, con base al estado actual de dicha matriz.

- Actualiza los resultados de estudios de prospectiva simulando el efecto de nuevas hipótesis y políticas de desarrollo.

- Cuantifica los beneficios energéticos, económicos y ambientales de una diversificación de la matriz energética, de la aplicación de medidas de eficiencia energética o un cambio en los patrones de consumo final.
- Analiza alternativas para enfrentar eventos críticos, como agotamiento de reservas, restricción o encarecimiento de fuentes energéticas importadas, entre otros.

El SAME es un sistema computacional, provisto de un tablero de control virtual, que permite obtener un panorama integral de los efectos que una determinada política en el sector energético, aplicada a corto, mediano o largo plazo. El sistema de planificación SAME permite la generación de un conjunto de indicadores de la matriz energética de un país o una región. Entre los indicadores más importante del sistema de planificación SAME destacan:

- Equilibrio en el balance de energía final.

- Estructura de la matriz de oferta y de consumo

- Factor medio de emisiones de Gases de Efecto Invernadero

- Costo medio de la oferta interna de energía.

- Índice de renovabilidad de la matriz energética

- Índice de suficiencia o soberanía energética

- Eficiencia en el consumo final.

- Alcance de reservas y potenciales.

- Matriz de la generación eléctrica.

La pantalla SAME permite simular el incremento de penetración de electricidad en el sector residencial. Así, el desplazamiento de electricidad en el sector residencial causaría un déficit en la oferta energética que podría ser suministrada por sistemas renovables de generación eléctrica. 
La reducción de consumo de GLP permitiría reducir las importaciones de recursos fósiles y proporcionar un efecto positivo en la reducción de emisiones de efecto invernadero.

\subsection{Escenario 100\% Transporte Terrestre Eléctrico}

En el Ecuador, en un hipotético escenario de sustitución total del diésel y gasolina por vehículos eléctricos en el transporte terrestre, el consumo de 36 mil 558 kbep de diésel y gasolina del año 2014 es inicialmente proyectado al año 2035, en un escenario denominado BAU, Bussiness As Usual, Figura 13. Se observa que, si no se implementan políticas de sustitución de derivados de petróleo, al año 2035, el diésel y gasolina conformarán el mayor porcentaje del suministro energético en el sector del transporte terrestre, con un total de 133.040,73 kbep.
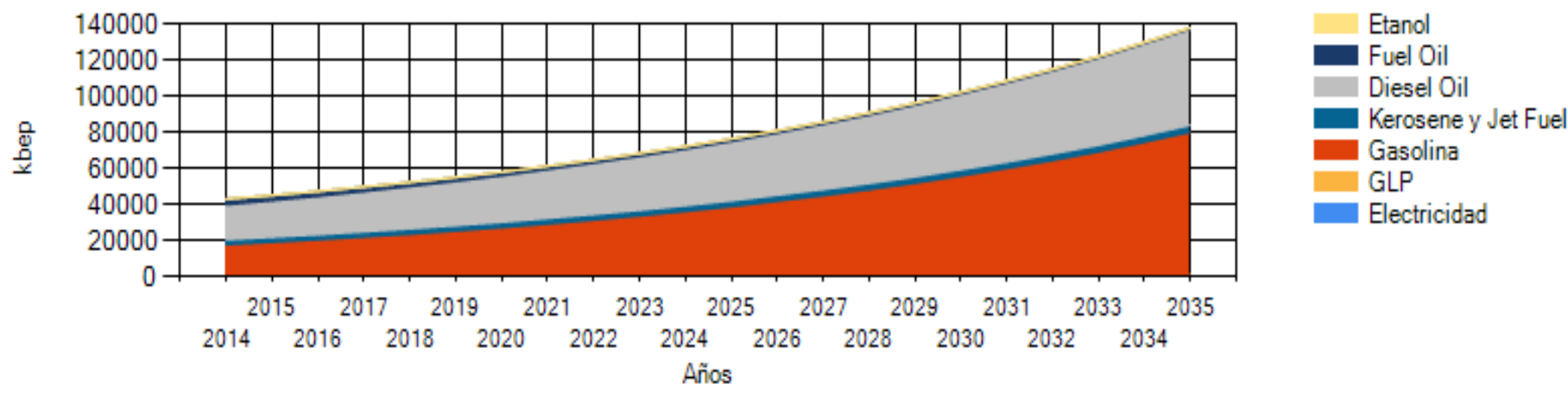

Figura 13. Evolución del consumo energético en el sector transporte por tipo de combustible al año 2035, en un escenario BAU.

El SAME dispone de un tablero de control virtual que permite sustituir el consumo de diésel y gasolina en el transporte del Ecuador. Al sustituirse el consumo de diésel y gasolina, en el año 2035, se genera un desbalance energético.

Puesto que el Ecuador, al año 2035, importará 105.873,90 kbep de diésel, una estrategia de sustitución permitirá reducir el consumo de diésel en el transporte igual a 86.223,0 kbep del total de importaciones. Debido a que el diésel se consume el sector comercial, residencial y en la construcción, a pesar de la importante reducción del consumo de diésel, se deberá importar 19.650,9 kbep.

Para minimizar el remanente de importaciones, se deberá implementar acciones adicionales para reducir el consumo del diésel en otros sectores de la economía ecuatoriana. El SAME permite eliminar las importaciones asociadas al consumo de diésel en el transporte, garantizando el balance energético del diésel en el sistema energético, Figura 14.

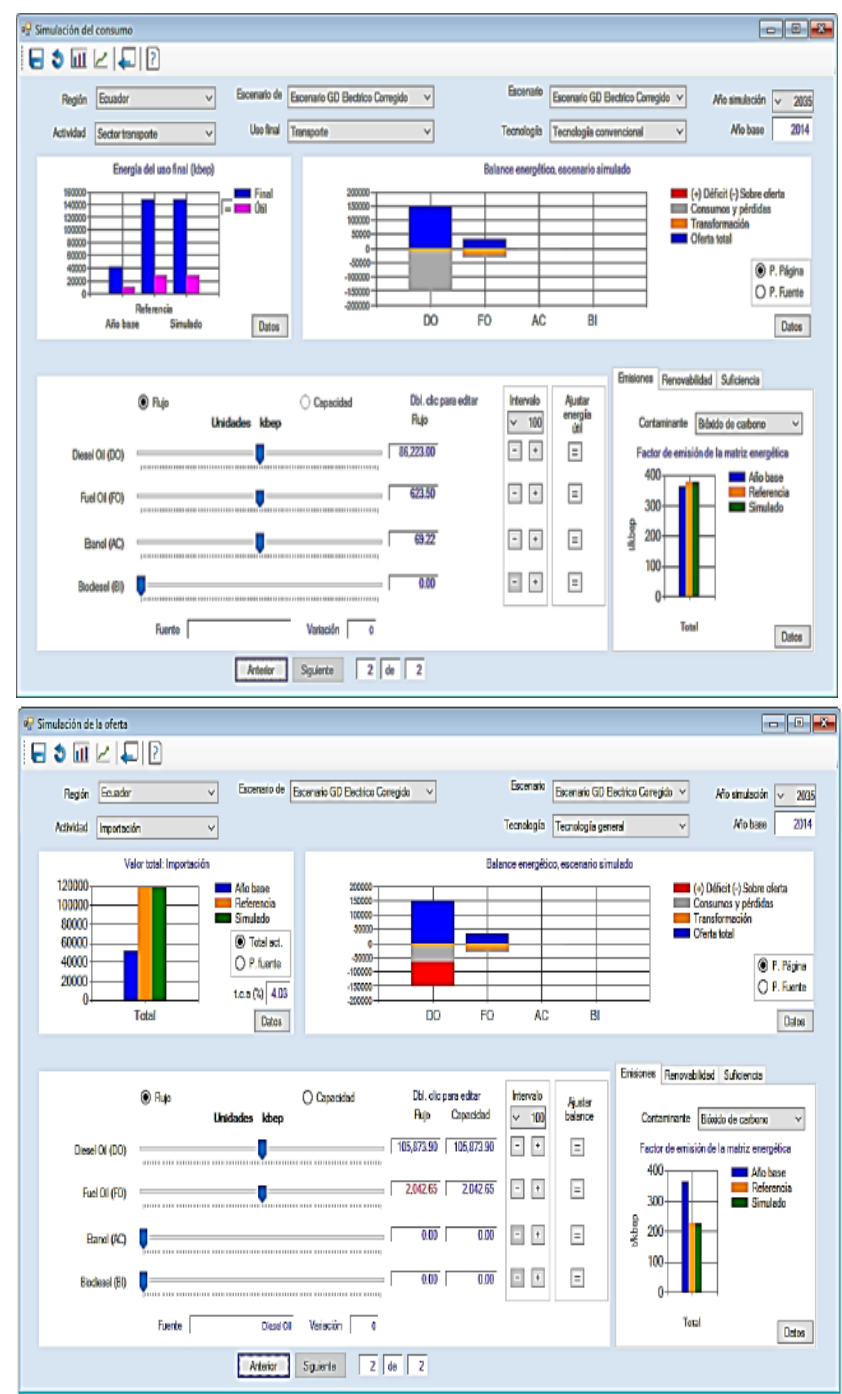

Figura 14. Balance Energético de los combustibles fósiles en el Ecuador para el escenario base. 
En el caso de la gasolina, el $96 \%$ de la producción e importación de gasolina se dedica al sector transporte. Las refinerías del Ecuador suministran el $40 \%$ del consumo nacional de gasolina y un pequeño volumen de gasolinas se exporta. Al sustituirse los 55.883,49 kbep de gasolina del transporte terrestre, se eliminan el total de las importaciones de gasolinas correspondientes al 2035 al valor de 44.803,06 kbep.

El remanente de gasolina restante iguala a 11.080,43 kbep se deberá exportar para que el SAME pueda equilibrar la cadena energética de la gasolina al sustituirse la gasolina por electricidad, Figura 15. Al año 2035, con la sustitución de todo el consumo de gasolina en el transporte, el país tendría capacidad de exportar un total de 13.917,31 kbep.
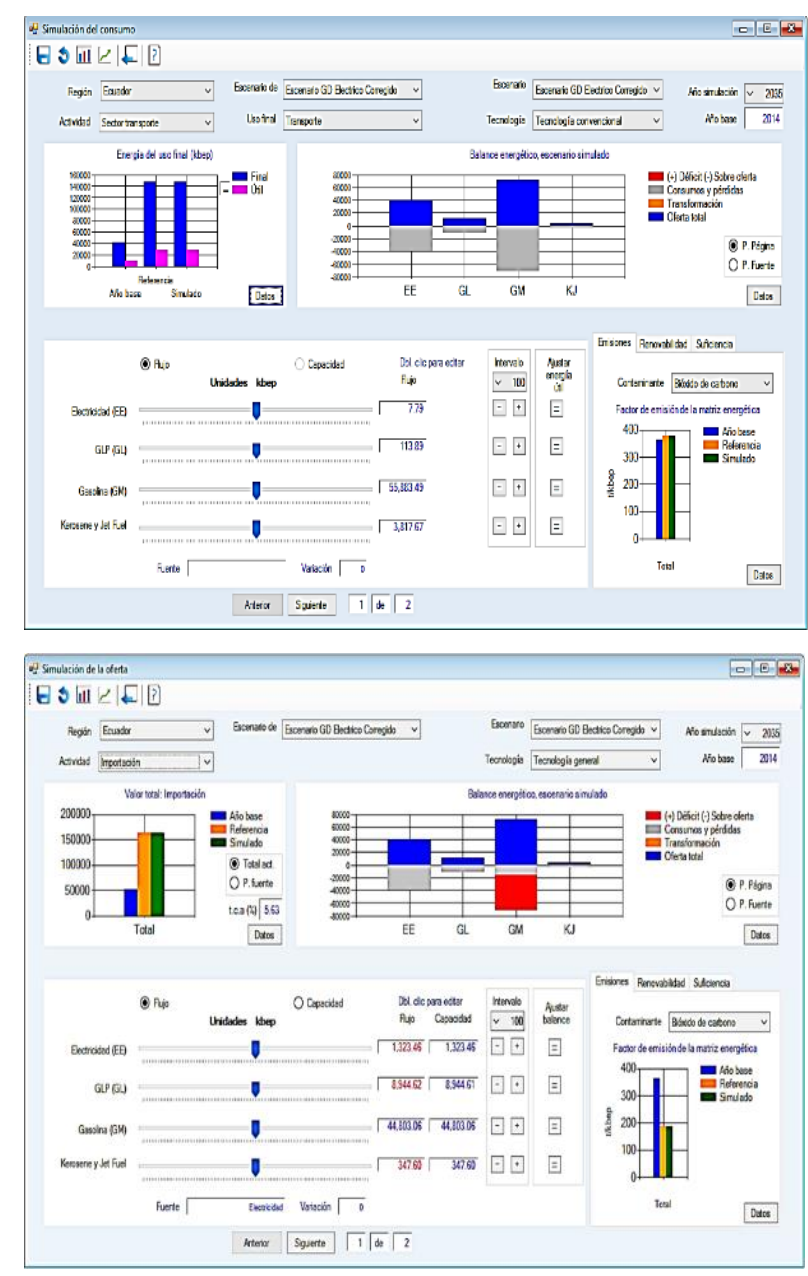

Figura 15. Balance Energético de los combustibles fósiles en el Ecuador para el escenario de simulación.

La sustitución del diésel y gasolina por electricidad genera un déficit de generación eléctrica, que deberá ser cubierta por las centrales eléctricas al año 2035, Figura 16. Se observa que para el año 2035, la generación eléctrica se incrementa de 17.285,34 kbep a 43.014,54 kbep, es decir, para sustituir la demanda en el transporte terrestre de 142.106,49 kbep, correspondiente a diésel y gasolina, se necesitará 25.729,2 kbep de energía eléctrica, Figura 16.
Una vez realizados los equilibrios energéticos en el diésel, gasolina y generación eléctrica, el SAME realiza una simulación evolutiva regresiva desde el año 2035 hasta el año 2014, año inicial de simulación, considerando el año 2014 como año base. La mencionada simulación permite visualizar la evolución del consumo de diésel y gasolina en el transporte terrestre del Ecuador. El consumo de diésel y gasolina se incrementan hasta alcanzar un pico máximo, para posteriormente reducirse hasta alcanzar un valor igual a cero en el año 2035, Figura 17
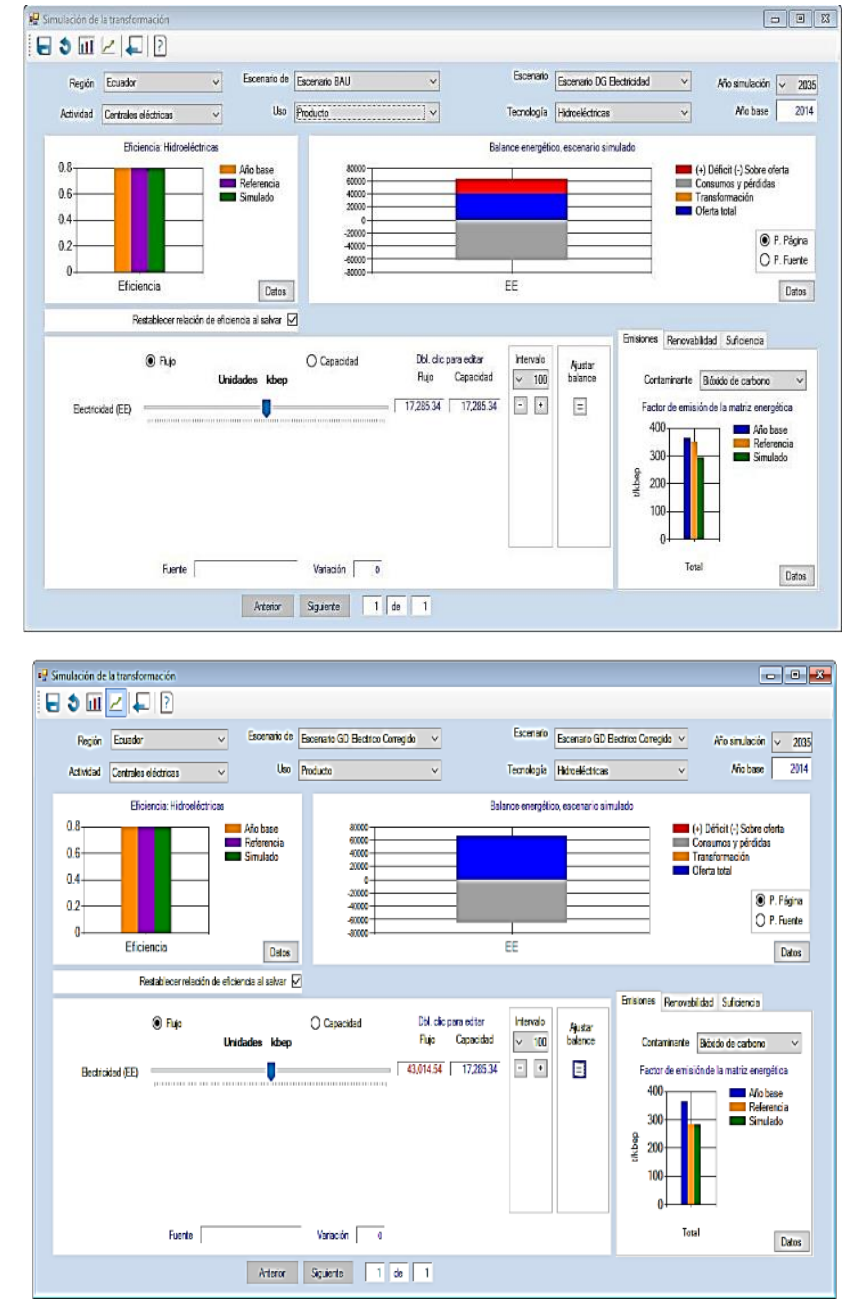

Figura 16. Simulación del Balance Energético ante la sustitución de electricidad por combustibles fósiles en el horizonte 2014-2035.

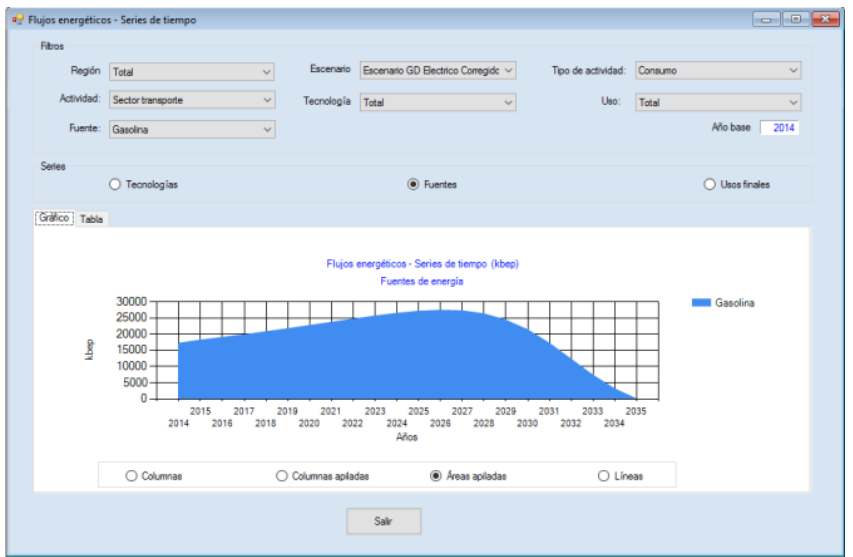

Figura 17. Proyección del comportamiento de combustibles fósiles gasolina al año 2035 
Asimismo, de forma paralela, la generación eléctrica suministra la energía necesaria para sustituir el diésel y gasolina por vehículos eléctricos, maximizando su producción de electricidad al año 2035, Figura 18.

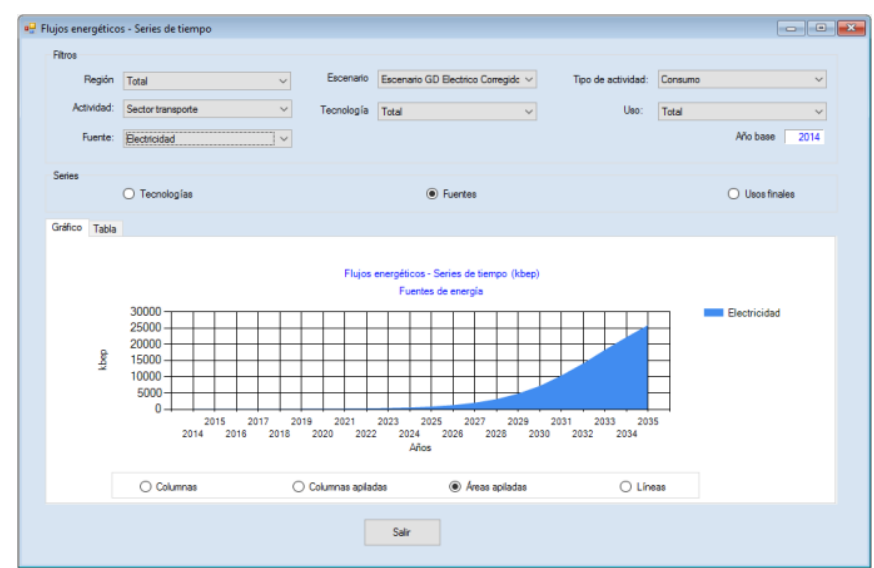

Figura 18. Incidencia causada por la sustitución de electricidad por gasolina en el transporte terrestre del Ecuador al año 2035.

Finalmente, en la Figura 19, se presenta la evolución de las fuentes de energía en el sector del transporte del Ecuador. Se observa que a pesar de la reducción de la gasolina y el diésel, aún existe un consumo energético asociado al kerosene/jet fuel, al fuel oil y a etanol. Asimismo, la electricidad en el año 2035 juega un rol predominante en el suministro energético del sector transporte del Ecuador, reduciendo la dependencia de los derivados de petróleo y las emisiones de gases de efecto invernadero.

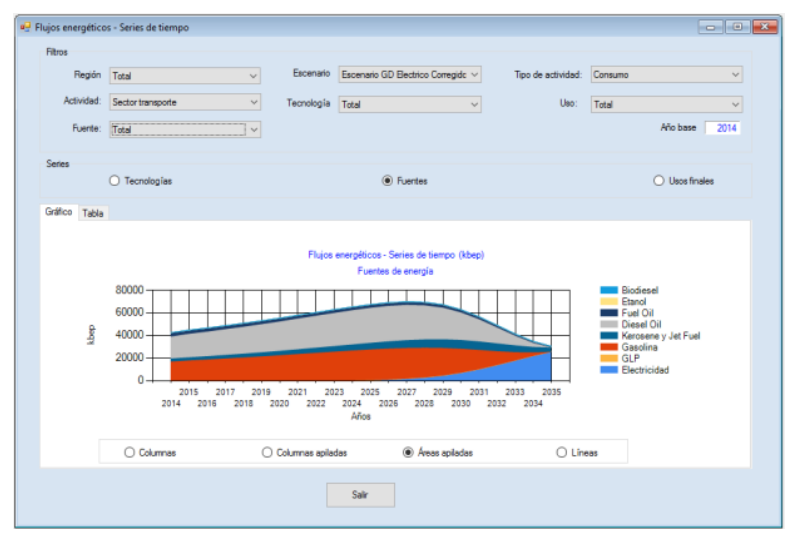

Figura 19. Transición de los combustibles fósiles y de la electricidad al año 2035 con el cambio de la matriz energética.

\section{CONCLUSIONES}

La estrategia de una futura implementación de vehículos eléctricos en el sector transporte permitiría una reducción de 86.223,0 kbep de diésel del consumo nacional, además, se eliminarían las importaciones de gasolina.

El volumen de diésel importado en el año 2035 sería alrededor de 19.650,9 kbep, que se consumen en los sectores comercial, residencial y construcción. Si en el año 2035, el Ecuador dejase de consumir combustibles fósiles tendría una capacidad de volumen de exportación de gasolina equivalente a 13.917,31 kbep.

En el Ecuador, en un hipotético escenario de sustitución total del diésel y gasolina por vehículos eléctricos, en el transporte terrestre, supondría una eficiencia relativa de la electricidad en 5,5 veces mayor a la de los combustibles fósiles.

\section{AGRADECIMIENTOS}

Los autores desean agradecer al Secretaria de Educación Superior, Ciencia, Tecnología e Innovación, SENESCYT, por su especial apoyo en el desarrollo de la presente propuesta, gracias a la financiación del Proyecto de Investigación PROMETEO: "Evaluación Técnico-Económica y Medioambiental de la Integración de Energías Renovables y Técnicas de Diseño y Gestión Eficiente en Sistemas de Edificación y Transporte Sostenibles, Aplicación Práctica a la Ciudad de Ambato", y a la Dirección de Investigación y Desarrollo, DIDE de la Universidad Técnica de Ambato por su especial apoyo en el desarrollo de la presente propuesta gracias a la financiación del proyecto "Planificación y Optimización del Sistema Integral de Transporte Electrificado y Movilidad Sostenible en la Ciudad de Ambato". Finalmente, agradecemos a la Dirección de Tránsito, Transporte y Movilidad del Gobierno Autónomo Descentralizado Municipalidad de Ambato, GADMA, por facilitarnos la información de los contratos de operación de las cooperativas de transporte urbano de la ciudad de Ambato.

\section{REFERENCIAS}

Energ, D. E. L. A. I., Industrial, S., Residencial, S., Ie, L., Ie, L., Ie, L., \& Ie, L. (2014). I. Conclusiones y recomendaciones, $1-28$.

Estratégicos, M. C. de S. (2015). Balance Energético Nacional 2015. Ministerio Coodinador de Sectores Estrategicos, 48. https://doi.org/10.1017/CBO9781107415324.004

Garc, F., Direcci, E. D. E. L. A., Estudios, D. E., Semana, P., \& Econom, D. E. L. A. (2013). SITUACIÓN ACTUAL Y PERSPECTIVAS DEL SECTOR ENERGÉTICO EN.

IDAE Instituto para la Diversificación y Ahorro de la Energía. (2005). Combustibles y vehículos alternativos, 7-11.

INER. (2013). Identificación de Necesidades de Eficiencia Energética en Transporte.

INER. (2014). Eficiencia energética en Transporte, 1-10. https://doi.org/10.1093/molbev/mst271

INER. (2017). INER. (E. Z. A. Parodi, Ed.). Quito. https://doi.org/9789942862068

SAME - OLADE. (n.d.). Retrieved October 30, 2018, from http://www.olade.org/producto/same-2/ 
Yascaribay, C., \& Vidal, W. (2016). Determinación del consumo de combustible de vehículos en base a los ciclos de conducción EPA FTP75 y EPA HWFET en dinamómetro de chasis, 2(Ftp 75), 1-7.

\section{BIOGRAFÍAS}

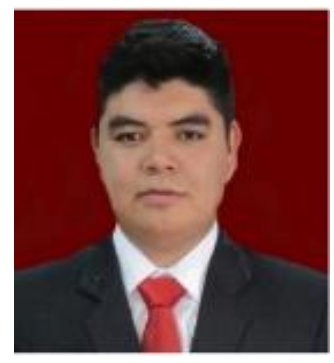

Carlos Luis Vargas Guevara. Nació en Ambato, Ecuador en 1991. Ingeniero en Electrónica y Comunicaciones por la Universidad Técnica de Ambato, 2015. Asistente de Investigación en la Unidad Operativa de Investigación y Desarrollo de la Facultad de Ingeniería en Sistemas, Electrónica e Industrial de la Universidad Técnica de Ambato. En la actualidad se encuentra realizando sus estudios de Posgrado en la Escuela Politécnica Nacional en la Maestría en Electricidad mención Redes Eléctricas Inteligentes.

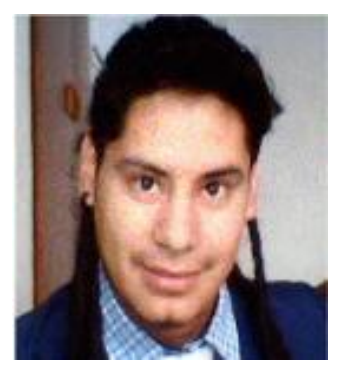

Jesús Guamán Molina. Nació en Latacunga, Ecuador en 1990. Ingeniero en Electrónica y Comunicaciones por la Universidad Técnica de Ambato, 2015. Desde el año 2015, trabaja en calidad de Asistente de Investigación en la Unidad Operativa de Investigación y Desarrollo de la Facultad de Ingeniería en Sistemas, Electrónica e Industrial de la Universidad Técnica de Ambato. En la actualidad se encuentra realizando sus estudios de Posgrado en la Escuela Politécnica Nacional en la Maestría en Electricidad mención Redes Eléctricas Inteligentes.

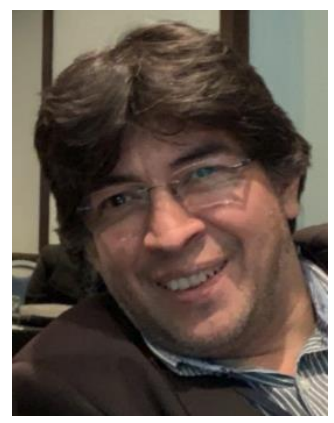

Alberto Ríos Villacorta. Dr. Ingeniero Eléctrico por Universidad Carlos III de Madrid, 2007. Master en Energías Renovables por la Universidad Europea de Madrid, 2004. Ingeniero Eléctrico en Sistemas y Redes Eléctricas por el Instituto Politécnico de Bielorrusia, 1993. Profesor Ayudante de la Universidad Carlos III de Madrid, 1998 - 2001. Profesor Adjunto de la Universidad Europea de Madrid, 2001-2014. Director Técnico del Laboratorio de Ensayos de Turbinas Eólicas y Simulaciones de parques Eólicos, Energy to Quality, 20052006. Director del Master Oficial de Energías Renovables de la Universidad Europea de Madrid, 2007-2011. Investigador Postdoctoral en la Universidad Técnica de Ambato entre los años 2014 y 2017, Beca Prometeo, SENESCYT, Ecuador. Profesor Titular Principal de la Universidad Técnica de Ambato desde el año 2017. Consultor Internacional, Especialista en Energías Renovables y Eficiencia

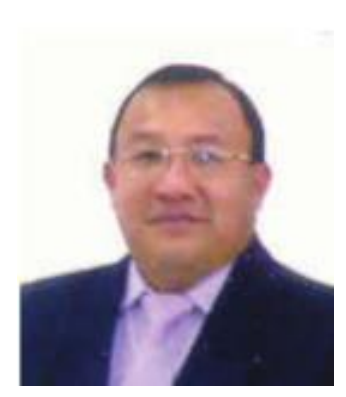

Manuel Otorongo Cornejo. Nació en Ambato, Ecuador. Ingeniero eléctrico en sistemas eléctricos de potencia, Escuela Politécnica Nacional, Master en redes/ telecomunicación en la Universidad Técnica de Ambato, culminó sus estudios de economía en la Facultad de ciencias económicas, Universidad Central del Ecuador. Ha sido Presidente del Comité técnico nacional de normalización para transformadores de distribución (2002-2007, 2010-2011). Fue Jefe de Área y Jefe de Sección en Empresa Eléctrica Ambato S.A., Especialista, Director y Gerente de Distribución en Empresa Eléctrica Quito. Actualmente es Profesor en la Universidad Técnica de Ambato. Sus áreas de interés son la Planificación, Optimización y Automatización de los Sistemas de Distribución. 